\title{
NMDA-gated ion channel research and its therapeutic potentials in neurodegenerative diseases: a review
}

This article was published in the following Dove Press journal:

Journal of Receptor, Ligand and Channel Research

24 November 2009

Number of times this article has been viewed

\author{
Maryam Majdi' \\ Huei-Sheng Vincent Chen ${ }^{1,2}$ \\ 'Center for Neuroscience, Aging \\ and Stem Cell Research, Burnham \\ Institute for Medical Research, \\ La Jolla, California, USA; ${ }^{2}$ Division of \\ Cardiology, University of California, \\ San Diego, San Diego, California, USA
}

Correspondence: Maryam Majdi or $\mathrm{H}$-SVincent Chen

Burnham Institute for Medical Research, I090 I North Torrey Pines Road, La Jolla, California 92037, USA

$\mathrm{Tel}+\mathrm{I} 858646-3183$

Fax +I $858795-5273$

Emailmmajdi@burnham.org or

hsv_chen@burnham.org

\begin{abstract}
The $N$-methyl-D-aspartate (NMDA) subtype of glutamate receptor (NMDAR) is essential for normal function of the central nervous system (CNS). Classical NMDARs, activated by glycine and glutamate, are heteromultimers comprising NR1 and NR2 subunits. Nonetheless, excessive activation of NMDARs by excitatory amino acids such as glutamate is thought to mediate neuronal damage in many neurological disorders. The dual role of NMDARs in normal and abnormal functioning of the CNS imposes significant constraints on possible therapeutic strategies aimed at ameliorating neurodegenerative diseases. To create safe NMDAR-based therapies, blockade of excessive NMDAR activity must therefore be achieved with minimal interference on its normal neuronal function. In general, NMDAR antagonists can be classified pharmacologically according to the site of action on the receptor-channel complex. These include drugs acting at the agonist sites (NMDA and glycine), channel pore, and modulatory sites. Both competitive NMDA and glycine antagonists result in generalized inhibition of NMDAR activities and have, thus, failed in clinical trials. Open-channel blockers with uncompetitive antagonism and drugs modulating NMDAR activities are appealing therapeutic strategies because, in theory, these properties could decrease neurotoxicity due to excessive levels of glutamate while sparing physiological neurotransmission. We review here NMDAR-related research that may lead to future therapeutic intervention against neurotoxicity.
\end{abstract}

Keywords: excitotoxicity, open-channel block, uncompetitive antagonism, Alzheimer disease, memantine

\section{Introduction}

Glutamate receptors are essential for normal function of the central nervous system (CNS), such as long-term potentiation (LTP) responsible for memory. ${ }^{1}$ However, excessive activation of NMDA subtype of glutamate receptor (NMDAR) is thought to mediate neuronal damage during pathological conditions such as stroke, Alzheimer's disease (AD), Parkinson's disease (PD), Huntington's disease (HD), and amyotrophic lateral sclerosis. ${ }^{2,3}$ The fine line between the physiological function and toxic reactions elicited by NMDARs is a major concern for developing safe therapeutic interventions. NMDAR antagonists can be categorized pharmacologically into 4 major groups according to the site of action on the receptor channel complex: Drugs acting at the 1) NMDA (agonist) recognition site, 2) glycine (co-agonist) site, 3) channel pore, and 4) modulatory sites such as the redox modulatory site, proton sensitive site, highaffinity $\mathrm{Zn}^{2+}$ site, and polyamine site. ${ }^{4}$ NMDARs are found in most regions of the brain; ${ }^{1}$ therefore, both competitive NMDA and noncompetitive glycine antagonists, although effective in preventing glutamate-mediated neurotoxicity, will cause generalized 
inhibition of glutamate receptor function. ${ }^{5}$ Such a side effect clearly limits their potential for future clinical applications. Therapeutic strategies involving modulatory agents acting at ligand-binding or modulatory sites of NMDARs may provide a better therapeutic index. Furthermore, openchannel block with uncompetitive antagonism is currently the most appealing strategy for therapeutic intervention during excessive NMDAR activation. This property, in theory, leads to a higher degree of channel blockade in the presence of excessive levels of glutamate and little blockade at relatively lower levels, for example, during physiological neurotransmission. ${ }^{6,7}$ Utilizing this pharmacological strategy of action, we helped develop memantine as the first clinically tolerated, yet effective agent against NMDAR-mediated neurotoxicity. ${ }^{7}$ Memantine has been clinically demonstrated to be effective in treating moderate-to-severe AD, while being well tolerated. ${ }^{7}$ Other strategies of creating NMDAR modulatory agents to combat neurodegenerative diseases will also be briefly discussed.

\section{NMDA receptor structure}

The glutamatergic neurotransmitter system comprises the majority of excitatory synapses in the neocortex. ${ }^{8}$ Based on the pharmacology of agonist sites, there are three classes of glutamate-gated ion (or ionotropic) channels, known as $\alpha$-amino-3-hydroxy-5-methyl-4-isoxazolepropionate (AMPA), kainate, and NMDA receptors. Three gene families are known to encode for NMDA receptor families, termed NMDAR1 (NR1), NMDAR2 (NR2), ${ }^{9}$ and NMDAR3 (NR3). ${ }^{10,11}$ In contrast to non-NMDA (AMPA and kainate)-type glutamate receptors, all functional NMDARs are heteromultimers. ${ }^{9}$ A common structural scheme for glutamate receptors contains an extracellular amino-terminal domain (ATD) for various modulatory functions, extracellular S1S2 domains for agonist binding, an ion channel domain with four transmembrane segments (M1-4) for gating and ion permeation, and a carboxy-terminal domain for communicating with intracellular milieu (Figure 1A-B). Conventional NMDARs composed of NR1 and NR2A-D subunits require dual agonists, glutamate and glycine, for activation (Figure 1). 7,9,12 The activity of NMDAR-associated channels is modulated by voltage-dependent block of magnesium $\left(\mathrm{Mg}^{2+}\right)$ and the channel manifests high permeability to calcium $\left(\mathrm{Ca}^{2+}\right){ }^{4,13}$ Depolarization of the postsynaptic membrane through activation of adjacent non-NMDA glutamate receptors (eg, AMPA receptors) in synaptic spines removes $\mathrm{Mg}^{2+}$ blockade and enables NMDA channel activation. Amino acid residues at or adjacent to the so called N-site or
"Q/R/N" (glutamine/arginine/asparagine)-site in the second membrane region (M2) of NMDAR subunits control the permeability and block of NMDAR-activated channels by $\mathrm{Ca}^{2+}$ and $\mathrm{Mg}^{2+} \cdot{ }^{13}$ Mutation of the N-site asparagine in NR1 or NR2 subunits also dramatically decreases the potency of antagonism by organic open-channel blockers, eg, MK-801, ketamine, amantadine, and memantine. ${ }^{14,15}$ Included within the NMDAR structure are various modulatory sites, such as the polyamine, redox, $\mathrm{Zn}^{2+}$, and proton sites (Figure 1C), which regulate NMDAR function. ${ }^{4,16}$

Structurally, NMDARs are likely composed of a tetramer of NR1 and NR2 subunits. The subunit composition determines the properties of receptor-ion channel complex. ${ }^{9,17} \mathrm{NR} 2$ subunits dictate overall pharmacological and biophysical properties of the NMDAR complex, and determine whether NMDARs will be involved in induction of LTP or synaptic plasticity. ${ }^{17}$ Alternative splicing of NR1 subunits further contributes to the diversity of pharmacological properties of NMDARs. ${ }^{18}$ NMDAR subunits are differentially expressed both regionally in the brain and temporally during development. For example, NR2B-containing NMDARs with slow-decaying currents are predominantly found in the early postnatal brain; NR2A outnumber NR2B subunits as the brain matures. ${ }^{19,20}$ This developmental switch of NR2 subunits results in differential properties of synaptic NMDARs, which may contribute to synaptic development or plasticity. ${ }^{19,21}$ Additionally, co-expression of the novel NR3 family of NMDAR subunits decreases the magnitude of NR1/NR2 receptor-mediated currents or forms glycine-activated channels with the NR1 subunit alone. ${ }^{10,11}$ Physiological function of NR3-containing receptors remains to be determined.

\section{NMDA receptors and normal synaptic neural function}

Most neurons (and also glia) in brain tissue contain high intracellular concentrations of glutamate $(\sim 10 \mathrm{mM}){ }^{7}$ Upon accumulation into synaptic vesicles, glutamate is released for a very brief period (on the order of milliseconds) during normal glutamatergic neurotransmission in order to communicate with other neurons through synaptic terminals (Figure 2). It is well established that activation of NMDARs is required for synaptic plasticity in normal neural function, such as LTP and long-term depression (LTD). ${ }^{17,21,22}$ LTP (or LTD) is an activity-dependent form of increased (or decreased) transmission efficacy at synapses which is considered to represent the cellular basis for learning and memory. ${ }^{22}$ Many neurodegenerative diseases and brain aging, which are associated with cognitive decline, display a decrease in LTP and 


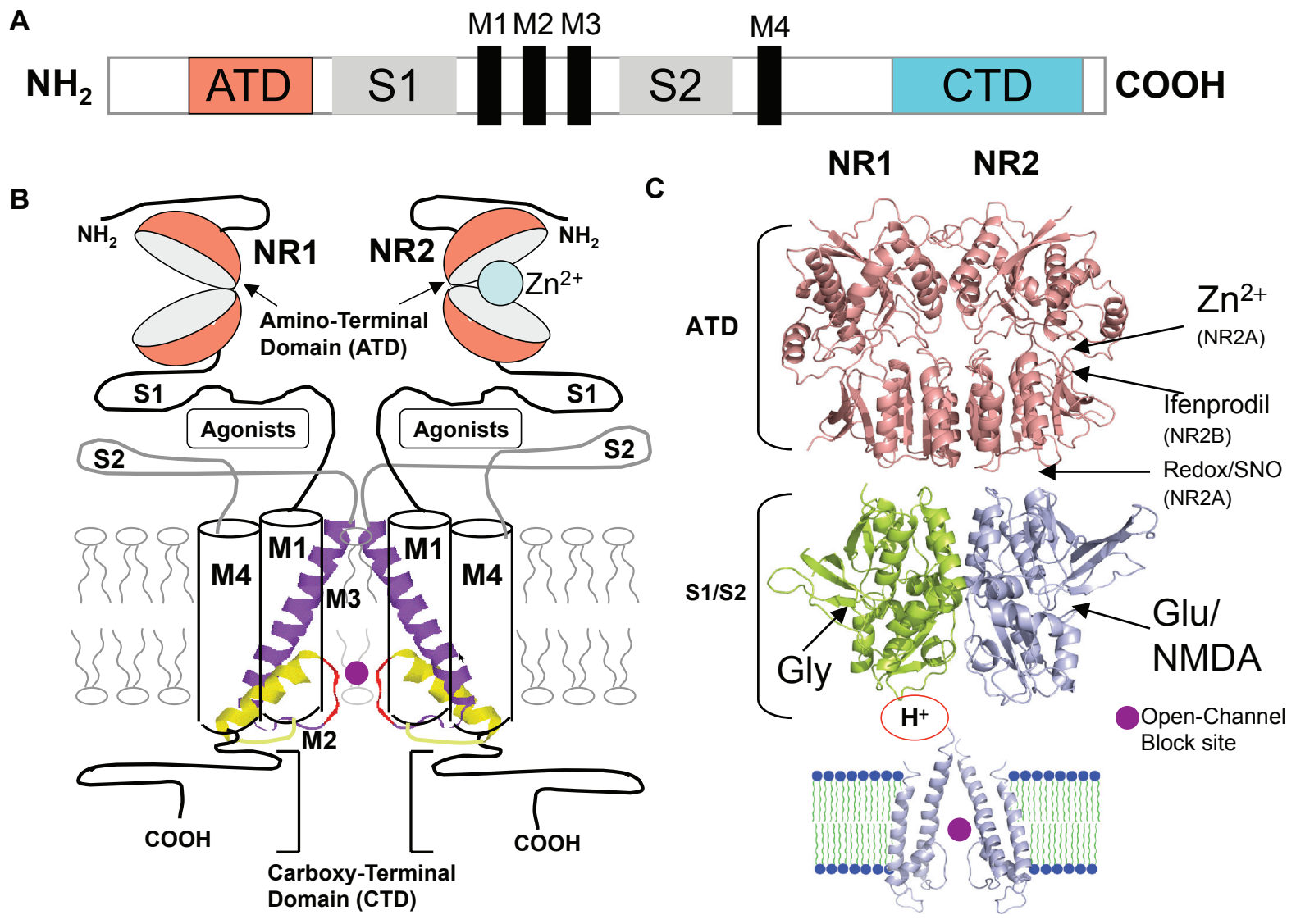

Figure I Schematic illustration of various models of the $\mathrm{N}$-methyl-D-aspartate receptor (NMDAR) indicating important binding and modulatory sites. A) Linear sequence of NMDAR. ATD: amino terminal domain; SI and S2: agonist binding domains; MI-4: the four transmembrane domains; CTD: carboxyl terminal domain. B) 3D schematic representation of various domains of the classical NMDAR subunit. C) Heterodimeric organization of the NRI/NR2 NMDAR. PDB entries used to construct the domain structures are: transmembrane domains: KcsA (grey), IBL8; agonist-binding domains: NRI (green) and NR2A (blue), 2A5T; and ATD domains: R2-ATD (dark pink): 3H5V. Glu or NMDA: glutamate or NMDA binding site. Gly: glycine binding site. $\mathrm{Zn}^{2+}$ : zinc binding site. NRI: NMDAR subunit I. NR2: NMDAR subunit 2A. Redox/SNO: cysteine sulfhydryl group (-SH) reacting with redox agents and nitric oxide species (NO). Open-channel block site: $\mathrm{Mg}^{2+}$, MK- $80 \mathrm{I}$, and memantine binding sites within the ion channel pore region. $\mathrm{H}^{+}$: proton-sensitive sites.

reduced synaptic plasticity. ${ }^{23-26}$ While both LTP and LTD require NMDAR activation, the level of postsynaptic $\mathrm{Ca}^{2+}$ increases after differential NMDAR activation may determine the types of synaptic modification. ${ }^{27}$ Importantly, NR2A- or NR2B-containing NMDARs may play differential roles in the induction and polarity of synaptic plasticity, that is LTP versus LTD. ${ }^{21,28-31}$ Moreover, proper synaptic localization of NR2Bcontaining NMDARs might be important for the strength of physiological induction of LTP. ${ }^{32}$ Therefore, synaptic versus extrasynaptic NMDARs and their subunit compositions further contribute to their differential and diverse roles in neural plasticity ${ }^{30-32}$ and neuronal survival. ${ }^{33}$

\section{NMDA receptor and excitotoxicity}

During normal synaptic transmission, glutamate is released into the synaptic cleft and is available for activation of NMDARs for a very brief period of time (Figure 2), yet excess levels of glutamate or its presence for prolonged periods of time may elicit neuronal insults ultimately leading to cell death (Figure 3), also known as "excitotoxicity". $3,34,35$ In many areas of the CNS, the predominant form of neurotoxicity appears to be mediated by overactivation of NMDARs and subsequent influx or release of excessive $\mathrm{Ca}^{2+}$. $\mathrm{Ca}^{2+}$ overload could consequently lead to mitochondrial dysfunction, production of reactive oxygen species (ROS) and nitric oxide (NO) radicals, activation of protein kinases, phosphatases and pro-apoptotic pathways through second messenger cascades, resulting in cell death due to oxidative stress and excitoxicity $^{3,36-38}$ (also see legend for Figure 3).

Various insults can lead to excessive or prolonged release of glutamate within the nervous system resulting in excitotoxicity. For instance, copious levels of glutamate are released from damaged cells at the focus of insults during traumatic brain injury or cerebral ischemia following stroke. 


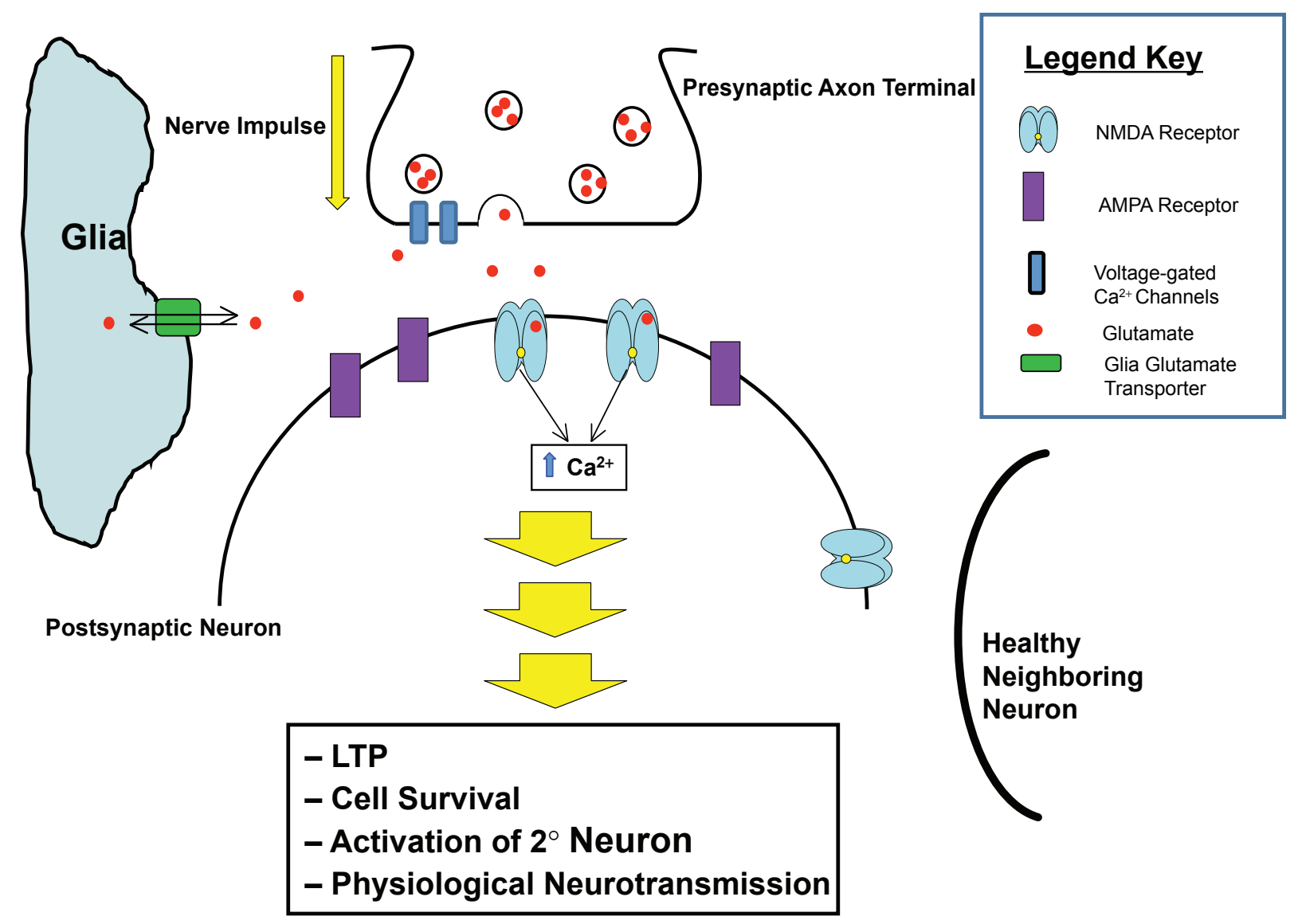

Figure 2 Schematic representation of normal N-methyl-D-aspartate (NMDA)-mediated neurotransmission. Glutamate binds to both synaptic and extrasynaptic NMDA receptors, postsynaptically. During physiological neurotransmission, AMPA receptors are transiently activated and are responsible for fast synaptic transmission. When a prolonged signal arrives at the synapse, more glutamate is released, resulting in further depolarization of the postsynaptic membrane. This depolarization aids in relieving the Mg2+ block of voltage-sensitive NMDARs, thus enabling $\mathrm{Ca}^{2+}$ ions to enter through the NMDAR ion channel pore. The increase in postsynaptic Ca ${ }^{2+}$ ions leads to a number of postsynaptic events which favor cell survival and physiological neurotransmission, including long-term potentiation (LTP) induction and activation of secondary neurons, which are crucial events necessary for learning and memory processes and for proper function of neuronal networks. Surrounding glia play a key role in the re-uptake of released glutamate via glia glutamate transporters, thereby ensuring glutamate removal from the synaptic cleft so as to avoid excessive receptor activation.

The resulting high concentrations of glutamate cause neighboring cells to depolarize, swell, lyse, and die by necrosis due to overactivation of NMDARs. Damaged cells at penumbral regions of the insult further release glutamate, resulting in a vicious cycle of auto-destructive events leading to progressive cell death that can continue for hours or even days following original injury. Furthermore, during ischemic insults many neurons are deprived of essential energy needed to maintain ionic homeostasis; as a result, these neurons depolarize and propagate the same type of auto-destructive events seen in traumatic injury. $2,3,7,36-38$

A subtler form of excitotoxicity has been implicated in many chronic and slowly progressive neurodegenerative disorders. Neurological diseases such as AD, HD, PD, multiple sclerosis, and amyotrophic lateral sclerosis are caused by various mechanisms but may share a final common pathway as a result of chronic, prolonged exposure to moderately elevated levels of glutamate relative to that occurring during normal neurotransmission, which ultimately leads to perturbed $\mathrm{Ca}^{2+}$ homeostasis, activation of apoptotic mechanisms and cell death (Figure 3). ${ }^{36-38}$ The extent of excitotoxicity from these chronic, subtle insults may also depend on activation of extrasynaptic NMDARs ${ }^{39}$ or NMDARs of different subunit compositions. . $^{3,33,39,40}$

Moreover, excitotoxicity can occur with normal levels of glutamate if the activity of NMDARs is increased, for example, when neurons are injured and become depolarized. As a result, the normal block of NMDAR-associated ion channels by $\mathrm{Mg}^{2+}$ is relieved; thereby enabling increased activity of NMDARs. ${ }^{7,40}$ In addition, increased activity of the enzyme NO synthase (NOS) is associated with excitotoxic cell death. ${ }^{38}$ The neuronal isoform of the enzyme is physically tethered to the NMDAR and activated by $\mathrm{Ca}^{2+}$ influx via 


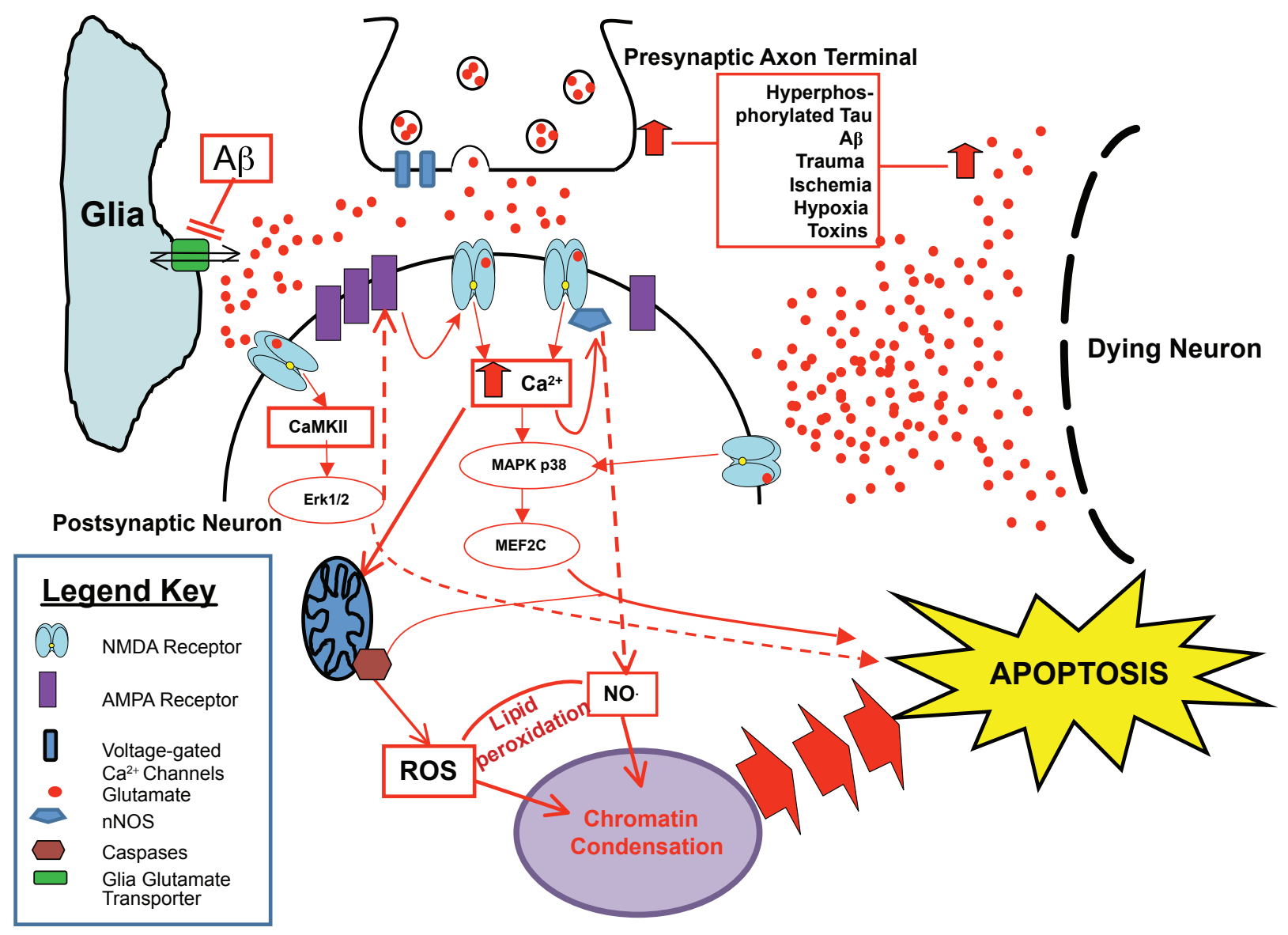

Figure 3 Schematic representation of the apoptotic-like cell death pathways triggered by excessive N-methyl-D-aspartate receptor (NMDAR) activity. While normal synaptic activation of NMDARs leads to physiological neurotransmission, excessive or prolonged glutamate release may result in activation of pro-apoptotic pathways, ultimately leading to cell death. Excessive glutamate may be released from neighboring neurons undergoing cell death; due to inhibition of glia glutamate transporters, preventing re-uptake of glutamate released into the synaptic cleft, or from presynaptic neurons which are undergoing various insults, such as $A \beta$-mediated toxicity, hyperphosphorylated tau, trauma, ischemia, hypoxia or under the influence of various neuronal toxins. Excess glutamate may then activate extrasynaptic NMDARs, as well as synaptic NMDARs resulting in an exaggerated increase in intracellular $\mathrm{Ca}^{2+}$ levels in the postsynaptic neuron. Abnormally elevated intracellular $\mathrm{Ca}^{2+}$ levels may lead to a cascade of events favoring apoptosis, such as activation of p38 mitogen activated kinase (MAPK)-MEF2C (transcription factor) pathway; activation of free radicals such as nitric oxide (NO) and reactive oxygen species (ROS); activation of $\mathrm{Ca}^{2+} /$ calmodulin-dependent kinase II (CaMKII) and extracellular-signal related kinases (ERKI/2) pathways; and activation of caspases which are associated with apoptotic pathways. Activation of ERKI/2 and related pathways by NMDAR overactivation could also lead to an increase in surface expression of AMPA receptors (AMPARs). Subsequent activation of AMPARs could in turn remove $\mathrm{Mg}^{2+}$ block of NMDARs and enhance NMDAR-mediated excitotoxicity.

the receptor-associated ion channel. Increased levels of NO have been detected in animal models of stroke and several neurodegenerative diseases..$^{3,7}$

Additionally, recent research suggested that induction of NMDAR-mediated neurotoxicity might depend on the NR2 subunit composition of NMDARs involved and their subcellular localization (synaptic versus extrasynaptic). 3,39,40 Overactivation of extrasynaptic NR2B-containing NMDARs appears to be associated with activation of many neurotoxic pathways and subsequent cell death; yet synaptic activation of NMDAR seems to be neuro-protective, supporting neuronal survival. Overactivation of NR2A- and/or NR2B-containing NMDARs have also been linked to mitochondrial dysfunction and elevated production of ROS and NO radicals in neurons, resulting in excitotoxicity. ${ }^{3,39-40}$
Other $\mathrm{Ca}^{2+}$-permeable channels and routes of $\mathrm{Ca}^{2+}$ entry, such as transient receptor potential (Trp), acid-sensing and $\mathrm{Ca}^{2+}$-permeable AMPA channels are also known to contribute to excitotoxicity. ${ }^{39,41-44}$ Apart from postsynaptic receptors, changes in various postsynaptic proteins, such as components of cytoskeletal actin-regulatory machinery and postsynaptic scaffold proteins (eg, PSD95/SAP90), are also thought to underlie the cognitive impairments involved with neurodegenerative disorders. ${ }^{43,45-50}$ It is also known that in the aged brain there is a progressive accumulation of neurotoxic compounds. ${ }^{51-54}$ This neurochemical change in the aged, cognitively impaired cerebral cortex could alter NMDARs and their corresponding neurotransmission. Furthermore, abnormal dendritic spine morphology and subsequent impaired function has been implicated in many neurological 
disorders associated with cognitive impairments, such as fragile $\mathrm{X}$ syndrome, $\mathrm{AD}$, and Down syndrome. ${ }^{55}$

\section{NMDA receptors and age-related cognitive decline}

Formerly, age- and AD-related cognitive impairments had been thought to occur due to a loss or decline of cholinergic neurons and functional integrity of the forebrain cholinergic systems. ${ }^{56,57}$ However, other neurotransmitter systems, which may contribute to the wide and complex range of cognitive deficits observed in the pathology of brain aging and various neurodegenerative diseases, have not been as extensively studied. ${ }^{58-60}$

In addition to the cholinergic system, the most consistent modification in the aging brain is a loss of glutamate receptors. ${ }^{61,62}$ Among the various excitatory glutamate receptors, NMDARs appear to be preferentially altered in the cerebral cortex during the aging process. ${ }^{63} \mathrm{~A}$ reduction of NMDAR density in the hippocampus and cortex of aging monkeys and rodents has been reported. ${ }^{62-65}$ Also, expression of various NMDAR subunits undergoes significant age-related alterations, which may ultimately affect the composition of NMDAR complexes and lead to changes in the binding properties, kinetics and physiological properties of NMDARs during brain aging. ${ }^{66-69}$ Thus, of the various age-related modifications, changes in postsynaptic NMDAR sites may be a major contributor to the behaviorally observed cognitive impairments associated with the aging process.

\section{NMDA receptors \\ and pathogenesis of AD}

There are several potential links between excitotoxic damage and the primary insults of $\mathrm{AD}$, which, based on rare familial forms of the disease, are believed to involve toxicity from misfolded mutant proteins. ${ }^{70,71}$ These proteins include soluble oligomers of $\beta$-amyloid peptide $(A \beta)$ and hyperphosphorylated tau proteins. ${ }^{71}$ For example, oxidative stress and increased intracellular $\mathrm{Ca}^{2+}$ generated by $\mathrm{A} \beta$ have been reported to enhance glutamate-mediated neurotoxicity in vitro. Additional experiments suggest that $A \beta$ can increase NMDA responses and thus excitotoxicity. ${ }^{72-74}$ Another potential link comes from recent evidence that glutamate transporters are down-regulated in $\mathrm{AD}$ and that $\mathrm{A} \beta$ can inhibit glutamate reuptake or even enhance its release. ${ }^{75,76}$ Moreover, excessive NMDAR activity has been reported to increase hyperphosphorylation of tau, which contributes to neurofibrillary tangles and is involved in NMDA-mediated neurotoxicity. ${ }^{77}$ The NMDAR antagonist, memantine, has been found to offer protection from these neurotoxic processes, as discussed below.

\section{NMDA receptors and other neurodegenerative diseases}

NMDARs play a key role in a variety of physiological processes. Either disruption in NMDAR activity or NMDAR overactivation has been implicated in the pathophysiology of a number of neurodegenerative disorders apart from AD. However, the role of NMDARs and the exact pathophysiological pathways involved in other neurodegenerative diseases, such as HD, remain to be determined.

HD is caused by degeneration of striatal medium spiny neurons. Striatal medium spiny neurons consist of a plethora of predominantly NR2B-containing NMDARs. ${ }^{78}$ Experimental evidence implicates NMDAR-mediated excitotoxicity as the underlying mechanism of neuronal loss and degeneration in HD ( $\mathrm{see}^{39,40,78-86}$ for details of experimental evidence); whereby an up-regulation of NR2B subunits occurs in HD. ${ }^{80}$ It has been demonstrated that NMDAR-mediated excitotoxicity of striatal neurons in transgenic mice could be ameliorated through specific antagonism of NR2B receptor subunits alone; ${ }^{81,82}$ however, a consensus regarding the primary mechanism of neuronal loss in HD is still lacking. ${ }^{83-85}$ Importantly, a NMDAR open-channel blocker, memantine has demonstrated moderate success with respect to the amelioration and delay in progression of HD in clinical trials. ${ }^{86}$

PD occurs as a result of degenerating nigral dopaminergic neurons and depletion of nigrostriatal dopamine. The dopaminergic deficit could lead to relative NMDAR overactivity and an increase of glutamatergic projections to the striatum and basal ganglia, resulting in further progressive neurodegeneration and clinical symptoms associated with PD. . $^{8788}$ As such, many studies have demonstrated that NMDAR antagonists could protect nigral neurons from excitotoxicity, ameliorate symptoms and slow disease progression of PD. ${ }^{87-91}$ Among various NMDAR antagonists, low affinity NMDAR antagonists, amantadine and memantine have demonstrated efficacy and tolerability towards alleviating PD-related symptoms and dementia. ${ }^{89,90}$ NR2B-subunit specific antagonist, CP-101,606 have also demonstrated efficacy in reducing PD-related symptoms with mild undesirable cognitive effects. $^{87,91}$

Other than neurodegenerative diseases, a disruption or overactivation in NMDAR activity is also implicated in a number of neurological disorders, such as epilepsy, major 
depression, chronic pain, ischemic and traumatic brain injury. We refer readers to several excellent review articles for an overview of NMDAR-mediated neurotoxicity in these diseases. ${ }^{3,87,88}$

\section{Drug design of NMDA receptor antagonists}

Excitotoxicity from overactivation of NMDARs has been implicated in a large number of acute or chronic neurological disorders; consequently, devising therapeutic strategies towards neuroprotection through combating excitotoxicity has drawn intense research interest. ${ }^{3-7,36,40}$ However, the major concern for potential therapeutic intervention at NMDARs is the fact that these receptors are involved in both normal neurotransmission and, if excessively activated, excitotoxic pathways. For clinical purposes, neuroprotective agents must block overactivation of NMDARs while preserving normal neurotransmission to avoid adverse effects due to generalized inhibition of normal NMDAR activity. Drugs that act as competitive antagonists at either glutamate or glycine agonist binding sites, block normal neurotransmission mediated by low levels of NMDAR activation more than overactivated NMDARs due to their competitive nature, thus depicting undesirable side effects or an unfavorable risk-benefit ratio for applications in clinical therapies. ${ }^{36,92}$ Furthermore, under excitotoxic conditions where high levels of glutamate exist, competitive antagonists at agonist-binding sites are likely displaced from NMDARs by competing levels of glutamate and will be less effective in preventing excitotoxicity. As such, lack of clinical benefit of these types of NMDAR antagonist in ameliorating stroke has been demonstrated. ${ }^{36,92}$ Nonetheless, partial agonists acting at the NMDAR glycine (agonist) site have been suggested with therapeutic potential as cognitive enhancers to combat age-related cognitive decline due to NMDAR loss..$^{93,94}$ The long-term effects and clinical utility of these NMDAR-dependent cognitive enhancers remain to be investigated. ${ }^{95}$ Allosteric modulators and uncompetitive open-channel blockers of NMDAR appear to have better clinical safety profiles and therapeutic potentials in combating neurodegenerative diseases.

\section{Uncompetitive antagonism and open-channel block}

When a drug is considered an open-channel blocker of NMDARs, it only indicates that this drug enters and blocks the ion channel when NMDARs are activated by dual agonists and in an "open-channel" conformation. However, it is the mode of "unbinding" from the NMDAR channel pore of open-channel blockers that determines their mechanisms of action (Figure 4). If an open-channel blocker can leave the channel pore in a closed or trapped conformation regardless of agonists binding, it would behave as a noncompetitive antagonist, and would not distinguish low from high levels of NMDAR activation (Figure 4A) ${ }^{96}$ On the other hand, an open-channel blocker that could only leave NMDAR channel pore after it re-opens by agonists would act as an "uncompetitive" antagonist (Figure 4B). ${ }^{96}$ Such "uncompetitive" antagonism, in theory, leads to a higher degree of channel blockade in the presence of excessive activation of NMDARs and little blockade at relatively lower levels of NMDAR activation (Figure 4C and see below). Pure uncompetitive antagonism through open-channel block is, therefore, an ideal approach for therapeutic purposes during excessive NMDAR activation, as a greater number of channels will be in the open-channel state and available for blocking while normal neurotransmission with lower levels of NMDAR activation would be relatively spared. ${ }^{6,96-98}$ Based upon these premises, an open-channel blocker would protect against more severe excitotoxic conditions as opposed to less severe conditions. Therefore, moderate-to-severe dementia that is associated with overactivation of NMDARs and subsequent cell injury and death, theoretically, would be more effectively treated by uncompetitive open-channel blockers relative to milder conditions.

\section{NR2 subunit-selective antagonism and extrasynaptic NMDA receptor blockade}

A new therapeutic strategy using NR2B-selective antagonists to target excitoxicity has recently emerged as extrasynaptic NR2B-containing NMDARs appear to be associated with glutamate-mediated excitotoxicity more than other NMDAR subtypes. Most NR2B-selective antagonists act as allosteric modulators on the ATD domain of NR2B subunits, displaying a higher affinity towards activated and desensitized conformations of NMDARs with a noncompetitive mode of action. ${ }^{99}$ However, NR2B-selective antagonists could display phencyclidine (PCP)-like behavioral effects and abuse potentials, as well as block the human ether-à-go-go (hERG) $\mathrm{K}^{+}$channel, which could lead to long QT-related lethal arrhythmias. Further development and clinical trials of these NR2B-selective compounds are needed to explore their therapeutic efficacy and potential adverse side effects in treating neurological diseases. Another potential strategy is targeting extrasynaptic NMDARs, since synaptic activation of NMDARs supports normal neurotransmission and neuronal survival while in pathological conditions, abnormal 
excitation of extrasynaptic NMDARs is frequently linked to excitotoxicity. ${ }^{39}$ However, further study is required to support the extrasynaptic targeting approach as extrasynaptic glutamate receptors are also rich in NR2B-containing NMDARs.

\section{Memantine as an NMDAR uncompetitive open-channel blocker}

To date, few NMDAR-targeted pharmacological agents have succeeded with adequate efficacy and acceptable side effects in randomized clinical trials for the treatment of neurological disorders. ${ }^{100}$ Memantine (MEM) and its analogues are the most well-tolerated and efficacious agents in this regard. MEM (1-amino-3,5-dimethyl-adamantane, Figure 4D) is a derivative of amantadine, an anti-influenza agent ${ }^{101}$ and has been used clinically with an excellent safety record for over 20 years in Europe to treat PD, spasticity, and AD. ${ }^{7,102}$ At clinically relevant concentrations $(1-12 \mu \mathrm{M}),{ }^{103-105}$ memantine acts as an open-channel, uncompetitive blocker of the NMDAR-coupled channel pore. ${ }^{6,96,106,107}$ We first reported that the extent to which a fixed, low-micromolar concentration of memantine blocked NMDAR activity actually increased as the NMDA concentrations increased during pathological situations (Figure 4C). ${ }^{6}$ As a result of this uncompetitive antagonism during therapeutic treatment, memantine exerts stronger blocking effects under pathological conditions due to excessive or prolonged glutamate-mediated excitotoxicity; while normal synaptic transmission, LTP and physiological responses to behavioral tests such as the Morris water maze are preserved. ${ }^{6,97,108}$ Memantine is currently the only nonacetyl cholinesterase inhibitor that is therapeutically approved for the treatment of patients with moderate to severe AD. The clinical tolerability and therapeutic potential of memantine is supported by safety and efficacy profiles in recent clinical trials for $\mathrm{AD}$ treatment. ${ }^{100,109}$

Additionally, at $<12 \mu \mathrm{M}$, memantine is relatively specific for NMDA-antagonistic action with a 50\% inhibition constant (IC50) of $\sim 1 \mu \mathrm{M}$ at $-60 \mathrm{mV}$, but is far below the effective level of memantine at most other receptor or ligand-gated channels (but see ${ }^{6,7}$ ). The therapeutic benefits of memantine in PD, and possibly cerebral ischemia, dementia, and epilepsy are, therefore, thought to occur via its antagonistic action on NMDARs. ${ }^{6,110,111}$

Neuroprotective agents that work by high-affinity binding to the NMDAR result in inhibition of the majority of all receptor activity, thereby yielding intolerable clinical side effects. ${ }^{36}$ Thus, open channel blockers with uncompetitive antagonism appear to be the best available strategy to combat excitotoxicity under pathological conditions while sparing physiological neurotransmission. ${ }^{6,7,96}$

\section{Other possible advantages of memantine action for its efficacy and safety profile}

One of most intriguing characteristics of memantine is its clinical safety profile accompanying its therapeutic efficacy when compared to other open channel blockers. A number of factors have been suggested to explain memantine's clinical tolerability and efficacy, including moderate-to-low affinity, moderate voltage dependence, fast blocking and unblocking kinetics, and partial trapping in the NMDAR-associated channel. ${ }^{70}$ The proposed explanations are based on the assumption that memantine and other open-channel blockers bind at the same site as extracellular $\mathrm{Mg}^{2+}$ in the channel selectivity filter. We showed that this assumption is incorrect. ${ }^{15} \mathrm{Mg}^{2+}$, a physiological open-channel blocker for NMDARs interacts differently on the N-site residues of NR1 and NR2 subunits when applied from the intracellular versus extracellular surface. ${ }^{112,113}$ We reported that the specific memantine blocking site is the intracellular $\mathrm{Mg}^{2+}$ blocking site, which is located at the N-site asparagine of the NR1 subunit and is slightly deeper than the extracellular $\mathrm{Mg}^{2+}$ blocking site. ${ }^{15}$ The $\mathrm{N}$ and $\mathrm{N}+1$ sites of NR2A subunits are the extracellular $\mathrm{Mg}^{2+}$ blocking site and provide the major electrostatic interaction with memantine upon binding to this deep, specific site (Figure 5). The distinct patterns of interaction of memantine with the channel selectivity filter ${ }^{6,15,96,110}$ may confer upon memantine unique kinetic features ${ }^{114}$ leading to the drug's excellent clinical tolerability. In accordance with these observations, in the absence of extracellular $\mathrm{Mg}^{2+}$, memantine displays minimal differences in blocking NMDARs containing various NR2 subunits. ${ }^{115}$

Furthermore, several studies have also reported a second binding site for memantine in NMDA-gated channels. ${ }^{115-118}$ We recently demonstrated that the second, superficial site of memantine action is nonspecific and may explain the noncompetitive (or nontrapping) component of memantine at near millimolar concentrations (Figure 4C). ${ }^{15,96}$ Occupancy by memantine of this shallow site would allow dissociation of the drug in either the open or closed conformation, resulting in a form of noncompetitive antagonism that would not confer advantages in clinical safety. ${ }^{15,96}$ Lipophilic leak of memantine from its blocking site cannot explain this noncompetitive component. ${ }^{119-120}$ Importantly, what renders 
A

\section{Non-competitive}

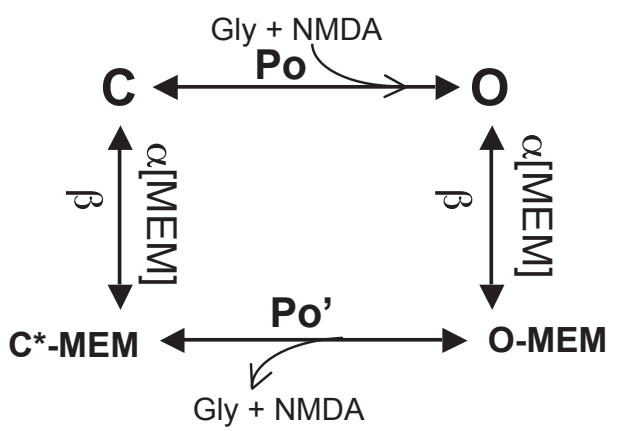

C

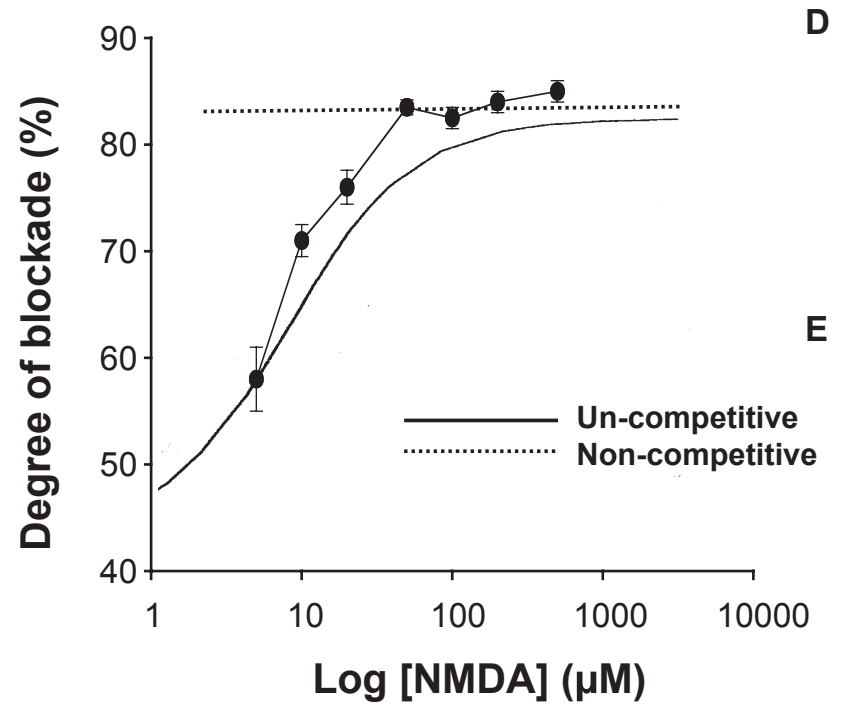

B

\section{Un-competitive}

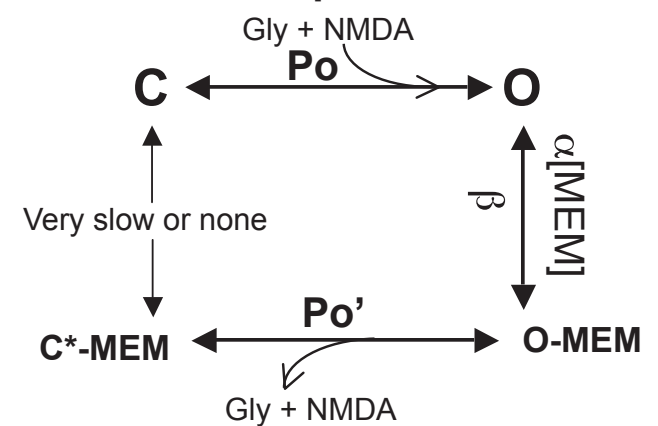

Gly + NMDA

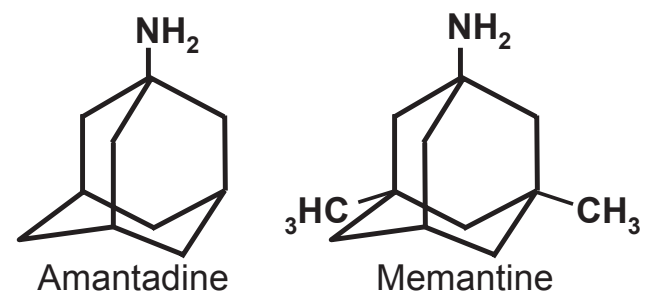

$\mathbf{E}$

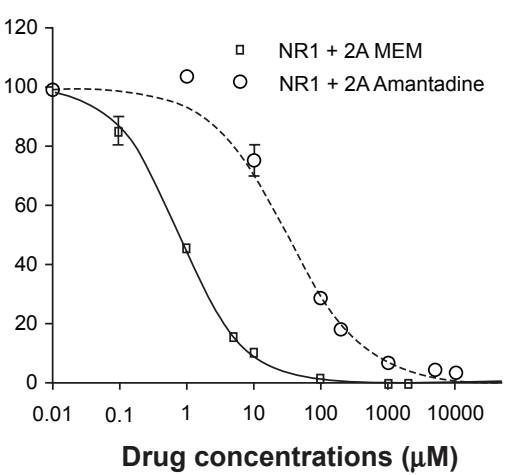

Figure $4 \mathrm{~A}$ comparison between noncompetitive and trapping/uncompetitive schemes of memantine (MEM) action. A) A scheme for noncompetitive antagonism with $C$ representing the closed channel; $O$, the open channel; $C^{*}-M E M$, the blocked and closed channel; O-MEM; the open but blocked channel; $\alpha$, the microscopic on-rate; $\beta$, the microscopic off-rate; [MEM], the concentration of MEM; and $\mathrm{P}$, the open probability of the channel. The affinity of the blocker for the closed and open channel is the same. The open probability of the unblocked channel is the same as that of the blocked channel. B) The scheme for uncompetitive antagonism. $\mathrm{P}_{\circ}$ ' is the open probability of the blocked channel, and the rest of the symbols have the same meaning as above. The blocker does not bind to or egress from the closed channel in this paradigm. C) Difference in predicted degrees of blockade between noncompetitive and uncompetitive antagonist action of MEM. Computer-simulated degree of blockade for a noncompetitive antagonist (dotted line) and uncompetitive antagonist (solid curve) with the models and parameters indicated in $\mathbf{A}$ and $\mathbf{B}$. The inhibition equilibrium constant ( $\mathrm{K}$ ) for the memantine blockade was assumed to be I. $2 \mu \mathrm{M}$ and the concentrations of memantine [MEM] was $6 \mu$ M.The empirical data points for low micromolar concentrations of MEM blockade were very close to those predicted theoretically for pure uncompetitive antagonism. At concentrations $\geq 100 \mu M$, MEM displayed a noncompetitive component of open channel block. Adapted from data of. ${ }^{96}$ D) Left: Chemical structure of amantadine. Right, Chemical structure of memantine, which has methyl group $\left(-\mathrm{CH}_{3}\right)$ side chains. E) Blockade of $200 \mu$ M NMDA-activated currents by amantadine or memantine. Dose-response curve for MEM constructed using $I_{\text {MEM }} / I_{\text {control }}$ (\%) versus MEM concentration. Data adapted from data of. ${ }^{15}$

memantine different from other so-called "low-affinity" NMDA open channel blockers is that the affinities of the two sites of memantine blockade are sufficiently distinct so that the pharmacological properties of memantine specific sites may account for its lack of side effects. ${ }^{15}$ In our hands, memantine, at therapeutic concentrations, displays minimal closed-channel block or egress (minimal lipophilic leak), and therefore behaves as a perfect uncompetitive blocker (Figure 5, see ${ }^{96}$ for details). Furthermore, $6 \mu \mathrm{M}$ memantine blocked $80 \%$ to $85 \%$ of extrasynaptic NMDAR-gated current (Figure 4E), ${ }^{6,15}$ but only $35 \%$ to $40 \%$ of NMDAR-mediated excitatory postsynaptic currents (EPSCs), ${ }^{97}$ indicating memantine exerts a preferential blockade of extrasynaptic NMDARs that are activated only during pathological insults. These additional blocking properties of memantine and its uncompetitive antagonism most likely account for its clinical tolerability and efficacy at low micromolar concentrations.

\section{Efficacy of memantine in animal models of neurological disorders}

The neuroprotective potential of memantine has been demonstrated in a large number of in vitro and in vivo animal 


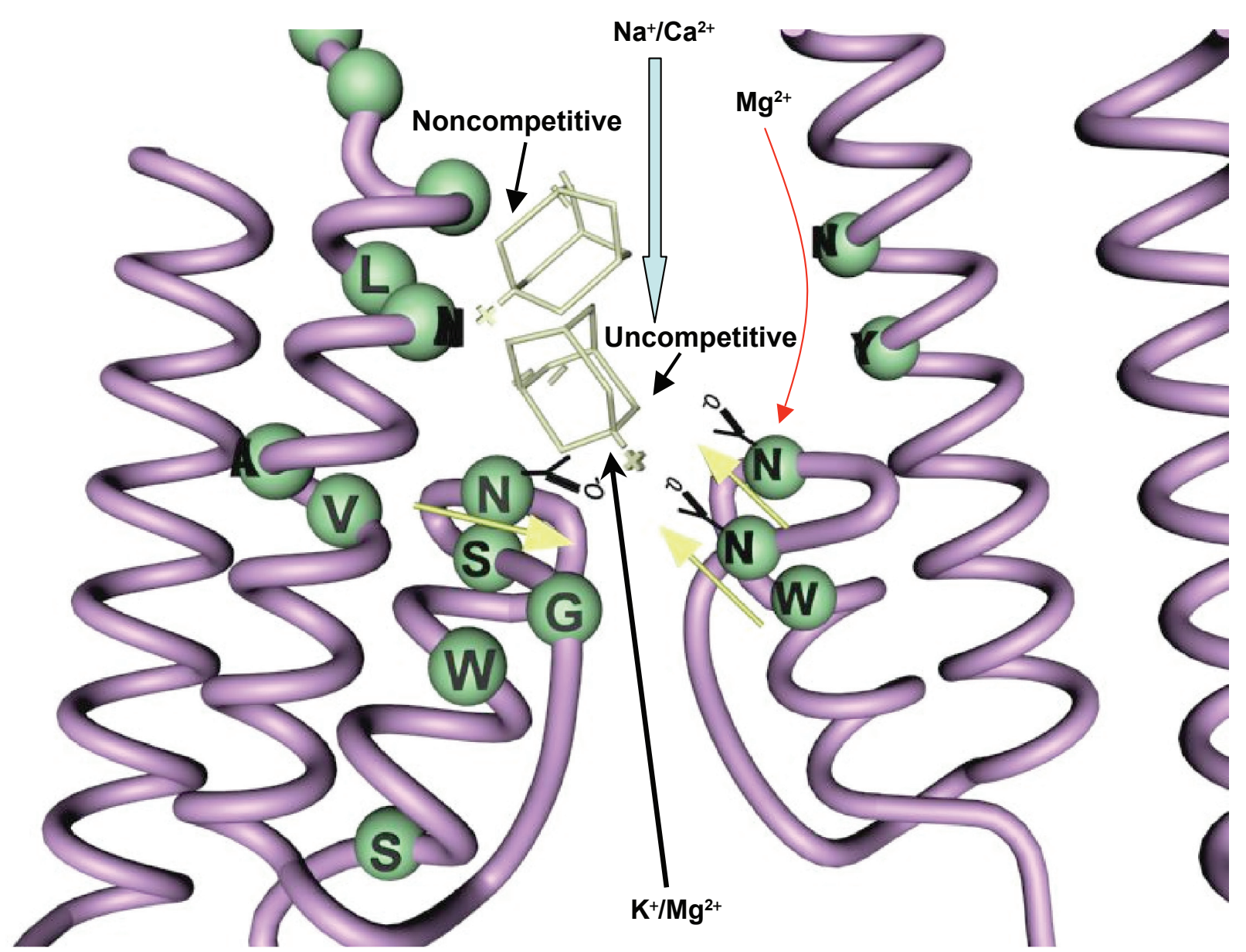

Figure 5 An atomic model illustrating two memantine (MEM) binding sites in the channel permeation pathway of the NMDAR. Locations of memantine binding sites in the channel permeation pathway are shown at the level of the channel selectivity filter (the specific and uncompetitive site) and at the L65I residue of the NRI subunit (the nonspecific and noncompetitive site). Permeant ions, $\mathrm{Na}^{+}, \mathrm{Ca}^{2+}$ and $\mathrm{K}^{+}$as well as nonpermeant blocker, $\mathrm{Mg}^{2+}$, can compete or interact with exogenously applied MEM for binding, and MEM binding interacts with the intracellular Mg² blocking site. ${ }^{15,96}$ Reproduced with Permission from Chen HSV, Lipton SA. Pharmacological implications of two distinct mechanisms of interaction of memantine with N-methyl-D-aspartate-gated channels.J Pharmacol Exp Ther. 2005;3। 4:96I-97I. ${ }^{15}$ Copyright (C 2005 American Society for Pharmacology and Experimental Therapeutics.

models by many laboratories (reviewed in ${ }^{108}$ ). For example, memantine has been shown to protect cerebrocortical, cerebellar and retinal neurons from NMDA-mediated neurotoxicity. ${ }^{6,97,121}$ In a rat stroke model, memantine reduced hypoxic-ischemic brain injuries by $30 \%$ to $50 \%$ when it was provided up to 2 hours following the ischemic event. ${ }^{6,97}$ Also, memantine treatment has been shown to decrease the loss of cholinergic neurons induced by NMDA-mediated toxicity or mitochondrial toxins in rat models. ${ }^{70}$ Furthermore, chronic infusion of memantine attenuated neuronal loss, improved short-term memory impairment, reduced learning deficits and neurotoxicity caused by quinolinic acid-induced cortical lesions in rat models. ${ }^{108}$
In terms of $\mathrm{AD}$ treatment, memantine was found to reduce neurotoxicity by preventing hippocampal neuronal loss and apoptosis instigated by intrahippocampal injection of $A \beta,{ }^{122}$ as well as by enhancing the processing of nonamyloidogenic $\beta$-amyloid precursor proteins. ${ }^{70}$ Although exact mechanisms by which memantine offers neuroprotection in in vivo or in vitro models of AD may be complex and remain to be determined, a mechanism associated with its NMDAR antagonism is favored. Nonetheless, memantine treatment significantly protected cultured rat cortical neurons against A $\beta$-induced toxicity by attenuating activation of caspase-3, hyper-phosphorylation of tau proteins and its associated signaling mechanisms. ${ }^{123}$ Memantine also improved performance on spatial behavioral tests in a transgenic mouse 
model of familial AD consisting of a mutant form of amyloid precursor protein and presenilin $1 .{ }^{124}$

Although exact mechanisms by which memantine offers neuroprotection and cognitive improvement in animal or culture models of AD remain to be determined and could be complex, a mechanism related to its NMDAR antagonism is favored. Several hypothetical and beneficial outcomes following memantine treatment have been suggested, including the resumption of optimal "signal to noise" ratio in synaptic activities, ${ }^{111}$ re-establishing the balance between inhibitory and excitatory neural networks and changing the balance of synaptic and extrasynaptic NMDAR activation for neuronal survival. $^{125}$

\section{Therapeutic potentials of memantine in human clinical trials}

A number of human clinical trials are completed or in progress to investigate the efficacy of memantine for the treatment of neuropathologies related to $\mathrm{AD}$, vascular dementia, HD, PD, traumatic brain injury, amyotrophic lateral sclerosis (ALS), frontotemporal lobe degeneration, neuropathic pain, depression, and glaucoma. ${ }^{100}$ Among these trials, the strongest evidence to date supports memantine as a therapy of choice for alleviating symptoms related to moderate-to-severe AD. ${ }^{109}$ In the 1990 s, 3 small clinical trials in Europe demonstrated that memantine (10-30 mg/day for 6-12 weeks) improved cognition, global functioning and activities of daily living (ADLs) in patients with AD and vascular dementia. ${ }^{100,109}$ Since 2000, 3 large ( $>250$ patients) randomized, placebo controlled trials and meta-analysis of their results in treating moderate to severe AD showed that memantine treatment $(20 \mathrm{mg} /$ day for 6-7 months) led to less deterioration in functional capacity and improved cognition, ADLs, and neuropsychiatric symptoms. ${ }^{100,126-128}$ Symptoms of agitation and aggression of AD patients in these trials were significantly improved following memantine treatment. In trials treating mild to moderate AD and vascular dementias, however, only small degrees of cognitive improvement had been demonstrated following memantine therapy $(20 \mathrm{mg} /$ day for $>6$ months). ${ }^{100}$ Also, clinical trials using memantine to treat neuropathic pain so far have yielded disappointing results with respect to its efficacy. ${ }^{129}$ Nonetheless, as we outlined above, the uncompetitive mode of memantine action would predict that, at a fixed dose, memantine should work better for severe conditions, eg, excessive glutamatemediated neurotoxicity causing cell death, than milder conditions manifested by slightly elevated glutamate-mediated neuro-deregulation. Bearing this into consideration, it is not surprising that memantine displayed a larger effect in moderate-to-severe dementia than in mild dementia. Most importantly, most clinical trials have revealed excellent clinical safety and tolerability of memantine treatment, with a frequency of adverse events similar to placebo. As a result, memantine is currently under extensive study for treatment of other neurodegenerative disorders, including HD, ALS and movement disorders.

\section{Conclusions and future perspective}

Glutamate receptor-mediated excitotoxicity is implicated in the pathogenesis of several neurological diseases and may be a common final pathway shared by many neurodegenerative disorders. This type of excitotoxicity is caused, at least in part, by excessive activation of NMDARs. However, NMDAR activity is also required for physiological neurotransmission. Many drugs that showed promise as inhibitors of excitotoxicity also blocked normal neuronal function and consequently depicted unacceptable side effects in clinical trials. ${ }^{7,36,111}$ In contrast, clinical trials in AD have demonstrated excellent safety profiles of memantine with minimal adverse side effects. We and others have shown that memantine is a relatively low-affinity open-channel blocker of NMDARs with uncompetitive antagonism at therapeutic concentrations. Memantine also exerts more blocking activity on extrasynaptic NMDARs, binds at the "intracellular" $\mathrm{Mg}^{2+}$ site in the channel pore and displays differential affinity for specific and nonspecific binding sites on the NMDAR. Due to its uncompetitive antagonism and unique interaction with permeant ions and $\mathrm{Mg}^{2+}$ in the channel pore, memantine prevents neurotoxicity from excessive NMDAR activation, yet spares low (physiological) levels of synaptic NMDAR activation during normal neurotransmission. These molecular interactions confer upon memantine favorable biophysical and pharmacological properties that contribute to the drug's clinical tolerability as well as its neuroprotective profile. ${ }^{7}$ Results from clinical studies have supported our hypothesis that low-affinity/uncompetitive memantine is a NMDAR-based therapeutic agent which exhibits promising efficacy in treating moderate-to-severe AD with an excellent safety profile.

Although the results of memantine trials are quite promising, it is imperative to continue exploring pharmacotherapies targeted towards various modulatory sites on NMDARs. Further investigation in this area may lead to future opportunities towards developing NMDAR 
subtype-specific modifying agents or extrasynaptic NMDAR blocking drugs that might inhibit excitotoxicity even more effectively and safely than memantine alone.

\section{Acknowledgments}

We thank Dr Rongsheng Jin for the NMDAR modeling shown in Figure 1C. This work was supported by an Early Career Development Award from American College of Cardiology Foundation, Bechtel Trusts and Foundation Grant, and California Institute of Regenerative Medicine (CIRM) Grants (RS1-00171-1 and RT1-01143) to H-S.V.C. Due to quickly expanding literature in basic research and clinical trials of therapies against NMDAR-related neurotoxicity, we could not cover every paper published and we express our sincere regret if we missed any important papers or research works.

\section{Disclosures}

The authors declare no conflicts of interest.

\section{References}

1. Nakanishi S. Molecular diversity of glutamate receptors and implications for brain function. Science. 1992;258:597-603.

2. Snider BJ, Gottron FJ, Choi DW. Apoptosis and necrosis in cerebrovascular disease. Ann NY Acad Sci. 1999;893:243-253.

3. Waxman EA, Lynch DR. N-methyl-D-aspartate receptor subtypes: multiple roles in excitotoxicity and neurological disease. Neuroscientist. 2005;11:37-49.

4. Yamakura T, Shimoji K. Subunit- and site-specific pharmacology of the NMDA receptor channel. Prog Neurobiol. 1999;59:279-298.

5. Willetts J, Balster RL, Leander JD. The behavioral pharmacology of NMDA receptor antagonist. Trends Pharmacol Sci. 1990;11: 423-428.

6. Chen HSV, Pellegrini JW, Aggarwal SK, et al. Open channel block of $N$-methyl-D-aspartate (NMDA) responses by memantine: Therapeutic advantage against NMDA receptor-mediated neurotoxicity. J Neuroscience. 1992;12:4427-4436.

7. Chen HSV, Lipton SA. The chemical biology of clinically tolerated NMDA receptor antagonists. J Neurochem. 2006;97(6):1611-1626.

8. Cull-Candy S, Brickley S, Farrant M. NMDA receptor subunits: diversity, development and disease. Curr Opin Neurobiol. 2001;11: $327-335$.

9. Wollmuth LP, Sobolevsky AI. Structure and gating of the glutamate receptor ion channel. Trends Neurosci. 2004;27:321-328.

10. Sucher NJ, Awobuluyi M, Choi YB, Lipton SA. NMDA receptors: from genes to channels. Trends Pharmacol Sci. 1996;17(10):348-355.

11. Chatterton JE, Awobuluyi M, Premkumar LS, et al. Excitatory glycine receptors containing the NR3 family of NMDA receptor subunits. Nature. 2002;415(6873):793-798.

12. Stephenson FA. Structure and trafficking of NMDA and GABAA receptors. Biochem Soc Trans. 2006;34:877-881.

13. Dingledine R, Borges K, Bowie D, Traynelis SF. The glutamate receptor ion channels. Pharmacol Rev. 1999;51:7-61.

14. Kashiwagi K, Masuko T, Nguyen CD, et al. Channel blockers acting at N-methyl-D-aspartate receptors: differential effects of mutations in the vestibule and ion channel pore. Mol Pharmacol. 2002;61(3): 533-545.
15. Chen HSV, Lipton SA. Pharmacological implications of two distinct mechanisms of interaction of memantine with $N$-methyl-Daspartate-gated channels. J Pharmacol Exp Ther. 2005;314:961-971.

16. Herin GA, Aizenman E. Amino terminal domain regulation of NMDA receptor function. Eur J Pharmacol. 2004;500(1-3):101-111.

17. Cull-Candy SG, Leszkiewicz DN. Role of distinct NMDA receptor subtypes at central synapses. Sci STKE. 2004:re16.

18. Zukin RS, Bennett MV. Alternatively spliced isoforms of the NMDAR receptor subunit. Trends Neurosci. 1995;18:306-313.

19. Bellone C, Nicoll RA. Rapid bidirectional switching of synaptic NMDA receptors. Neuron. 2007;55:779-785.

20. Kew JN, Richards JG, Mutel V, Kemp JA. Developmental changes in NMDA receptor glycine affinity and ifenprodil sensitivity reveal three distinct populations of NMDA receptors in individual rat cortical neurons. J Neurosci. 1998;18:1935-1943.

21. Liu L, Wong TP, Pozza MF, et al. Role of NMDA receptor subtypes in governing the direction of hippocampal synaptic plasticity. Science. 2004;304:1021-1024.

22. Martin SJ, Grimwood PD, Morris RG. Synaptic plasticity and memory: an evaluation of the hypothesis. Annu Rev Neurosci. 2000;23:649-711.

23. Barnes CA, Rao G, Foster TC, McNaughton BL. Region-specific age effects on AMPA sensitivity: electrophysiological evidence for loss of synaptic contacts in hippocampal field CA1. Hippocampus. 1992;2:457-468.

24. Barnes CA, Rao G, Shen J. Age-related decrease in the $N$-methyl-DaspartateR-mediated excitatory postsynaptic potential in hippocampal region CA1. Neurobiol Aging. 1997;18:445-452.

25. Kirkwood A, Silva A, Bear MF. Age-dependent decrease of synaptic plasticity in the neocortex of alphaCaMKII mutant mice. Proc Natl Acad Sci USA. 1997;94:3380-3383.

26. Tombaugh GC, Rowe WB, Chow AR, Michael TH, Rose GM. Thetafrequency synaptic potentiation in CA1 in vitro distinguishes cognitively impaired from unimpaired aged Fischer 344 rats. J Neurosci. 2002;22:9932-9940.

27. Nishiyama M, Hong K, Mikoshiba K, Poo MM, Kato K. Calcium stores regulate the polarity and input specificity of synaptic modification. Nature. 2000;408(6812):584-588.

28. Zhao MG, Toyoda H, Lee YS, et al. Roles of NMDA NR2B subtype receptor in prefrontal long-term potentiation and contextual fear memory. Neuron. 2005;47:859-872.

29. Toyoda H, Zhao MG, Zhuo M. NMDA receptor-dependent longterm depression in the anterior cingulate cortex. Rev Neurosci. 2006; $17: 403-413$.

30. Bartlett TE, Bannister NJ, Collett VJ, et al. Differential roles of NR2A and NR2B-containing NMDA receptors in LTP and LTD in the CA1 region of two-week old rat hippocampus. Neuropharmacology. 2007;52:60-70.

31. Li R, Huang FS, Abbas AK, Wigstrom H. Role of NMDA receptor subtypes in different forms of NMDA-dependent synaptic plasticity. BMC Neurosci. 2007;8:55.

32. WonGardoni F, Mauceri D, Malinverno M, et al. Decreased NR2B subunit synaptic levels cause impaired long-term potentiation but not long-term depression. J Neurosci. 2009;29:669-677.

33. Liu Y, Wong TP, Aarts M, et al. NMDA receptor subunits have differential roles in mediating excitotoxic neuronal death both in vitro and in vivo. $J$ Neurosci. 2007;27:2846-2857.

34. Olney JW. Glutamate-induced retinal degeneration in neonatal mice. Electron microscopy of the acutely evolving lesion. J Neuropathol Exp Neurol. 1969;28:455-474.

35. Olney JW, Ho OL. Brain damage in infant mice following oral intake of glutamate, aspartate or cysteine. Nature. 1970;227:609-611.

36. Danysz W, Parsons CG. Neuroprotective potential of ionotropic glutamate receptor antagonists. Neurotox Res. 2002;4(2):119-126.

37. Martin LJ, Al-Abdulla NA, Brambrink AM, Kirsch JR, Sieber FE, Portera-Cailliau C. Neurodegeneration in excitotoxicity, global cerebral ischemia, and target deprivation: A perspective on the contributions of apoptosis and necrosis. Brain Res Bull. 1998;46:281-309. 
38. Lipton SA, Nicotera P. Calcium, free radicals and excitotoxins in neuronal apoptosis. Cell Calcium. 1998;23:165-171.

39. Papadia S, Hardingham GE. The dichotomy of NMDA receptor signaling. Neuroscientist. 2007;13:572-579.

40. Paoletti P, Neyton J. NMDA receptor subunits: function and pharmacology. Curr Opin Pharmacol. 2007;7:39-47.

41. Turetsky DM, Canzoniero LM, Snsi SL, Weiss JH, Goldberg MP, Choi DW. Cortical neruones exhibiting kainite-activated $\mathrm{Co}^{2+}$ uptake are selectively vulnerable to AMPA/kainite receptor-mediated toxicity Neurbiol Dis. 1994;1:101-110.

42. Aarts M, Iihara K, Wej SL, et al. A key role for TRPM7 channels in anoxic neuronal death. Cell. 2003;115:863-877.

43. Xiong ZG, Zhu XM, Chu XP, et al. Neuroprotection in ischemia: blocking calcium-permeable acid-sensing ion channels. Cell. 2004;118:687-698.

44. Gao J, Duan B, Wang DG, et al. Coupling between NMDA receptor and acid-sensing ion channel contributes to ischemic neuronal death. Neuron. 2005;48:635-646.

45. Harigaya Y, Shoji M, Shirao T, Hirai S. Disappearance of actin-binding protein, drebrin, from hippocampal synapses in Alzheimer's disease. J Neurosci Res. 1996;43:87-92.

46. Hatanpaa K, Isaacs KR, Shirao T, Brady DR, Rapoport SI. Loss of proteins regulating synaptic plasticity in normal aging of the human brain and in Alzheimer disease. J Neuropathol Exp Neurol. 1999;58: 637-643.

47. Love S, Siew LK, Dawbarn D, Wilcock GK, Ben-Shlomo Y, Allen SJ. Premorbid effects of APOE on synaptic proteins in human temporal neocortex. Neurobiol Aging. 2006;27:797-803.

48. Tada T, Sheng M. Molecular mechanisms of dendritic spine morphogenesis. Curr Opin Neurobiol. 2006;16:95-101.

49. Zhao L, Ma QL, Calon F, et al. Role of p21-activated kinase pathway defects in the cognitive deficits of Alzheimer disease. Nat Neurosci. 2006;9:234-242.

50. Kojima N, Shirao T. Synaptic dysfunction and disruption of postsynaptic drebrin-actin complex: a study of neurological disorders accompanied by cognitive deficits. Neurosci Res. 2007; $58: 1-5$.

51. Cruz R, Almaguer MW, Bergado Rosado JA. Glutathione in cognitive function and neurodegeneration. Rev Neurol. 2003;36: 877-886.

52. Schipper HM. Brain iron deposition and the free radical-mitochondrial theory of ageing. Ageing Res Rev. 2004;3:265-301.

53. Harman D. Free radical theory of aging: an update: increasing the functional life span. Ann NY Acad Sci. 2006;1067:10-21.

54. Droge W, Schipper HM. Oxidative stress and aberrant signaling in aging and cognitive decline. Aging Cell. 2007;6:361-370.

55. Fiala JC, Spacek J, Harris KM. Dendritic spine pathology: cause or consequence of neurological disorders? Brain Res Brain Res Rev 2002;39:29-54.

56. Bartus RT, Dean RL 3rd, Beer B, Lippa AS. The cholinergic hypothesis of geriatric memory dysfunction. Science. 1982;217: 408-414.

57. Sparks DL, Hunsaker JC 3rd, Slevin JT, DeKosky ST, Kryscio RJ, Markesbery WR. Monoaminergic and cholinergic synaptic markers in the nucleus basalis of Meynert (nbM): normal age-related changes and the effect of heart disease and Alzheimer's disease. Ann Neurol. 1992;31:611-620.

58. Arnsten AF, Cai JX, Goldman-Rakic PS. The alpha-2 adrenergic agonist guanfacine improves memory in aged monkeys without sedative or hypotensive side effects: evidence for alpha-2 receptor subtypes. J Neurosci. 1988;8:4287-4298.

59. Ogura H, Aigner TG. MK-801 impairs recognition memory in rhesus monkeys: comparison with cholinergic drugs. J Pharmacol Exp Ther. 1993;266:60-64.

60. DeKosky ST. Pathology and pathways of Alzheimer's disease with an update on new developments in treatment. $J$ Am Geriatr Soc. 2003; 51(5 Supp1 Dementia):S314-S320.
61. Magnusson KR, Cotman CW. Age-related changes in excitatory amino acid receptors in two mouse strains. Neurobiol Aging. 1993; 14:197-206.

62. Castorina M, Ambrosini AM, Pacific L, Ramacci MT, Angelucci L. Age-dependent loss of NMDA receptors in hippocampus, striatum, and frontal cortex of the rat: prevention by acetyl-L-carnitine. Neurochem Res. 1994;19:795-798.

63. Peterson C, Cotman CW. Strain-dependent decrease in glutamate binding to the $N$-methyl-D-aspartic acid receptor during aging. Neurosci Lett. 1989;104:309-313.

64. Wenk GL, Walker LC, Price DL, Cork LC. Loss of NMDA, but not GABA-A, binding in the brains of aged rats and monkeys. Neurobiol Aging. 1991;12:93-98.

65. Kitamura Y, Zhao XH, Ohnuki T, Takei M, Nomura Y. Age-related changes in transmitter glutamate and NMDA receptor/channels in the brain of senescence-accelerated mouse. Neurosci Lett. 1992;137: $169-172$.

66. Kutsuwada T, Kashiwabuchi N, Mori H, et al. Molecular diversity of the NMDA receptor channel. Nature 1992;358:36-41.

67. Monyer H, Sprengel R, Schoepfer R, et al. Heteromeric NMDA receptors: molecular and functional distinction of subtypes. Science. 1992;256:1217-1221.

68. Gallagher M, Landfield PW, McEwen B, et al. Hippocampal neurodegeneration in aging. Science. 1996;274:484-485.

69. Kuehl-Kovarik MC, Magnusson KR, Premkumar LS, Partin KM. Electrophysiological analysis of NMDA receptor subunit changes in the aging mouse cortex. Mech Ageing Dev. 2000;115:39-59.

70. Rogawski MA, Wenk GL. The neuropharmacological basis for the use of memantine in the treatment of Alzheimer's disease. CNS Drug Rev 2003;9:275-308.

71. Selkoe DJ. Alzheimer's disease: genes, proteins, and therapy. Physiol Rev. 2001;81:741-766.

72. Koh JY, Yang LL, Cotman CW. Beta-amyloid protein increases the vulnerability of cultured cortical neurons to excitotoxic damage. Brain Res. 1990;533:315-320.

73. Mattson MP, Cheng B, Davis D, Bryant K, Lieberburg I, Rydel RE. beta-Amyloid peptides destabilize calcium homeostasis and render human cortical neurons vulnerable to excitotoxicity. J Neurosci. 1992;12:376-389.

74. Wu J, Anwyl R, Rowan MJ. Beta-Amyloid-(1-40) increases long-term potentiation in rat hippocampus in vitro. Eur J Pharmacol. 1995;284: $\mathrm{R} 1-\mathrm{R} 3$.

75. Topper R, Gehrmann J, Banati R, et al. Rapid appearance of betaamyloid precursor protein immunoreactivity in glial cells following excitotoxic brain injury. Acta Neuropathol (Berl). 1995;89:23-28.

76. Harkany T, Abraham I, Timmerman W, et al. beta-amyloid neurotoxicity is mediated by a glutamate-triggered excitotoxic cascade in rat nucleus basalis. Eur J Neurosci. 2000;12:2735-2745.

77. Couratier P, Lesort M, Sindou P, Esclaire F, Yardin C, Hugon J. Modifications of neuronal phosphorylated tau immunoreactivity induced by NMDA toxicity. Mol Chem Neuropathol. 1996;27:259-273.

78. Li L, Fan M, Icton CD, et al. Role of NR2B-type NMDA receptors in selective neurodegeneration in Huntington disease. Neurobiol Aging. 2003;24:1113-1121.

79. Fan MM, Fernandes HB, Zhang LY, Hayden MR, Raymond LA. Altered NMDA receptor trafficking in a yeast artificial chromosome transgenic mouse model of Huntington's disease. J Neurosci. 2007;27:37683779.

80. Heng MY, Detloff PJ, Wang PL, Tsien JZ, Albin RL. In vivo evidence for NMDA receptor-mediated excitotoxicity in a murine genetic model of Huntington disease. J Neurosci. 2009;29:3200-3205.

81. Levine MS, Klapstein GJ, Koppel A, et al. Enhanced sensitivity to $\mathrm{N}$-methyl-D-aspartate receptor activation in transgenic and knockin mouse models of Huntington's disease. J Neurosci Res. 1999;58:515-532.

82. Zeron MM, Hansson $\mathrm{O}$, Chen $\mathrm{N}$, et al. Increased sensitivity to $\mathrm{N}$-methyl-D-aspartate receptor-mediated excitotoxicity in a mouse model of Huntington's disease. Neuron. 2002;33:849-860. 
83. Cepeda C, Ariano MA, Calvert CR, et al. NMDA receptor function in mouse models of Huntington disease. J Neurosci Res. 2001;66: $525-539$.

84. Luthi-Carter R, Strand A, Peters NL, et al. Decreased expression of striatal signaling genes in a mouse model of Huntington's disease. Hum Mol Genet. 2000;22;9:1259-1271.

85. Cha JH, Frey AS, Alsdorf SA, et al. Decreased expression of striatal signaling genes in a mouse model of Huntington's disease. Hum Mol Genet. 2000;22; 9:1259-1271.

86. Beister A, Kraus P, Kuhn W, Dose M, Weindl A, Gerlach M. The N-methyl-D-aspartate antagonist memantine retards progression of Huntington's disease. J Neural Transm Suppl. 2004;68: 117-122.

87. Mony L, Kew JN, Gunthorpe MJ, Paoletti P. Allosteric modulators of NR2B-containing NMDA receptors: molecular mechanisms and therapeutic potential. Br J Pharmacol. 2009; 157:1301-1317.

88. Gardoni F, Di Luca M. New targets for pharmacological intervention in the glutamatergic synapse. Eur J Pharmacol. 2006;545:2-10.

89. Del Dotto P, Pavese N, Gambaccini G, et al. Intravenous amantadine improves levadopa-induced dyskinesias: an acute double-blind placebo-controlled study. Mov Disord. 2001;16:515-520.

90. Aarsland D, Ballard C, Walker Z, et al. Memantine in patients with Parkinson's disease dementia or dementia with Lewy bodies: a double-blind, placebo-controlled, multicentre trial. Lancet Neurol. 2009;8:613-618.

91. Nutt JG, Gunzler SA, Kirchhoff T, et al. Effects of a NR2B selective NMDA glutamate antagonist, CP-101,606, on dyskinesia and Parkinsonism. Mov Disord. 2008;23:1860-1866.

92. Lutsep HL, Clark WM. Neuroprotection in acute ischaemic stroke. Current status and future potential. Drugs R D. 1999;1:3-8.

93. Jansen M, Dannhardt G. Antagonists and agonists at the glycine site of the NMDA receptor for therapeutic interventions. Eur J Med Chem. 2003;38:661-670.

94. Burgdorf J, Zhang XL, Weiss C, et al. The N-methyl-D-aspartate receptor modulator GLYX-13 enhances learning and memory, in young adult and learning impaired aging rats. Neurobiol Aging. 2009. [Epub].

95. Wood PL. The NMDA receptor complex: a long and winding road to therapeutics. IDrugs. 2005;8:229-235.

96. Chen HSV, Lipton SA. Mechanism of memantine block of NMDAactivatedchannels in rat retinal ganglion cells: uncompetitive antagonism. J. Physiol (Lond). 1997;499:27-46.

97. Chen HSV, Wang YF, Rayudu PV. et al. Neuroprotective concentrations of the $N$-methyl-D-aspartate open-channel blocker memantine are effective without cytoplasmic vacuolation following post-ischemic administration and do not block maze learning or long-term potentiation. Neuroscience. 1998;86:1121-1132.

98. Rang HP. Drugs and ionic channels: mechanisms and implications. Postgrad Med J. 1981;89 Suppl 1:89-97.

99. Mony L, Kew JN, Gunthorpe MJ, Paoletti P. Allosteric modulators of NR2B-containing NMDA receptors: molecular mechanisms and therapeutic potential. Br J Pharmacol. 2009;157:1301-1317.

100. Kalia LV, Kalia SK, Salter MW. NMDA receptors in clinical neurology: excitatory times ahead. Lancet Neurol. 2008;7:742-755.

101. Tominack RL, Hayden FG. Rimantadine hydrochloride and amantadine hydrochloride use in influenza A virus infections. Infect Dis Clin North Am. 1987;1:459-478.

102. Fleischhacker WW, Buchgeher A, Schubert H. Memantine in the treatment of senile dementia of the Alzheimer type. Progr Neuro Psychopharmacol Biol Psych. 1986;10:87-93.

103. Wesemann W, Sturn G, Fünfgeld EW. Distribution and metabolism of the potential anti-parkinson drug memantine in the human. J Neural Transm (Suppl). 1980;16:143-148.

104. Hesselink MB, De Boer BG, Breimer DD, Danysz W. Brain penetration and in vivo recovery of NMDA receptor antagonists amantadine and memantine: a quantitative microdialysis study. Pharm Res. 1999;16, $637-642$.
105. Danysz W, Parsons CG, Quack G. NMDA channel blockers: memantine and amino-alkylcyclohexanes. In vivo characterization. Amino Acids. 2000;19:167-172.

106. Bormann J. Memantine is a potent blocker of $N$-methyl-D-aspartate (NMDA) receptor channels. Eur J Pharmacol. 1989;166:591-592.

107. Parsons CG, Gruner R, Rozental J, et al. Patch clamp studies on the kinetics and selectivity of $N$-methyl- $d$-aspartate receptor antagonism by memantine (1-amino-3,5-dimethyladamantan). Neuropharmacology. 1993;32:1337-1350.

108. Parsons CG, Danysz W, Quack G. Memantine is a clinically well tolerated N-methyld-aspartate (NMDA) receptor antagonist - a review of preclinical data. Neuropharmacology. 1999;38:735-767.

109. Robinson DM, Keating GM. Memantine: a review of its use in Alzheimer's disease. Drugs. 2006;66:1515-1534.

110. Rogawski MA. Low affinity channel blocking (uncompetitive) NMDA receptor antagonists as therapeutic agents - toward an understanding of their favorable tolerability. Amino Acids. 2000;19:133-149.

111. Parsons CG, Stöffler A, Danysz W. Memantine: a NMDA receptor antagonist that improves memory by restoration of homeostasis in the glutamatergic system - too little activation is bad, too much is even worse. Neuropharmacology. 2007;53:699-723.

112. Wollmuth L, Kuner T, Sakmann B. Adjacent asparagines in the NR2-subunit of the NMDA receptor channel control the voltagedependent block by extracellular $\mathrm{Mg}^{2+}$. J Physiol. 1998;506:13-32.

113. Wollmuth LP, Kuner $\mathrm{T}$, Sakmann B. Intracellular $\mathrm{Mg}^{2+}$ interacts with structural determinants of the narrow constriction contributed by the NR1-subunit in the NMDA receptor channel. J Physiol. 1998;506:33-52.

114. Yuan H, Erreger K, Dravid SM, Traynelis SF. Conserved structural and functional control of $N$-methyl-D-aspartate receptor gating by transmembrane domain M3. J Biol Chem. 2005;280:29708-29716.

115. Bresink I, Benke TA, Collett VJ, et al. Effects of memantine on recombinant rat NMDA receptors expressed in HEK 293 cells. Brit J Pharm. 1996;119:195-204.

116. Antonov SM, Johnson JW. Voltage-dependent interaction of openchannel blocking molecules with gating of NMDA receptors in rat cortical neurons. J Physiol (Lond). 1996;493:425-445.

117. Blanpied TA, Boeckman FA, Aizenman E, Johnson JW. Trapping channel block of NMDA-activated responses by amantadine and memantine. J Neurophysiol. 1997;77:309-323.

118. Sobolevsky AI, Koshelev SG, Khodorov BI. Interaction of memantine and amantadine with agonist-unbound NMDA-receptor channels in acutely isolated rat hippocampal neurons. J Physiol (Lond). 1998;512:47-60.

119. Mealing GA, Lanthorn TH, Small DL, et al. Structural modifications to an N-methyl-D-aspartate receptor antagonist result in large differences in trapping block. J Pharmacol Exp Ther. 2001;297: 906-914.

120. Bolshakov KV, Gmiro VE, Tikhonov DB, Magazanik LG. Determinants of trapping block of $N$-methyl-D-aspartate receptor channels. J Neurochem. 2003;87:56-65.

121. Osborne NN. Memantine reduces alterations to the mammalian retina, in situ, induced by ischemia. Vis Neurosci. 1999;16:45-52.

122. Miguel-Hidalgo JJ, Alvarez XA, Cacabelos R, Quack G. Neuroprotection by memantine against neurodegeneration induced by beta-amyloid(1-40). Brain Res. 2002;958:210-221.

123. Song MS, Rauw G, Baker GB, Kar S. Memantine protects rat cortical cultured neurons against beta-amyloid-induced toxicity by attenuating tau phosphorylation. Eur J Neurosci. 2008;28:1989-2002.

124. Minkeviciene R, Banjeree P, Tanila H. Memantine improves spatial learning in a transgenic mouse model of Alzheimer's disease. J Pharmacol Exp Ther. 2004;311:677-682.

125. Johnson JW, Kotermanski SE. Mechanism of action of memantine. Curr Opin Pharmacol. 2006;6:61-67.

126. Reisberg B, Doody R, Stoffler A, Schmitt F, Ferris S, Mobius HJ. Memantine in moderate-to-severe Alzheimer's disease. NEngl J Med. 2003;348:1333-1341. 
127. Tariot PN, Farlow MR, Grossberg GT, Graham SM, McDonald S, Gergel I. Memantine treatment in patients with moderate to severe Alzheimer disease already receiving donepezil: a randomized controlled trial. JAMA. 2004;291:317-324.

128. van Dyck CH, Tariot PN, Meyers B, Malca RE. A 24-week randomized, controlled trial of memantine in patients with moderate to severe Alzheimer disease. Alzheimer Dis Assoc Disord. 2007;21:136-143.
129. Rogers M, Rasheed A, Moradimehr A, Baumrucker SJ. Memantine (Namenda) for neuropathic pain. Am J Hosp Palliat Care. 2009; 26:57-59.

\section{Publish your work in this journal}

The Journal of Receptor, Ligand and Channel Research is an international, peer-reviewed, open access, online journal. The journal welcomes laboratory and clinical findings in the fields of biological receptors, ligands, channel and signal transduction research including: receptors and signalling; ligands; transporters, pores and channels; binding and activation; receptor regulation; role of receptors in diseases and their treatment; molecular basis of membrane structure and functions; molecular models of membranes. The manuscript management system is completely online and includes a very quick and fair peer-review system. Visit http://www.dovepress.com/ testimonials.php to read real quotes from published authors.

Submit your manuscript here: http://www.dovepress.com/journal-of-receptor-ligand-and-channel-research-journal 